\title{
Publication Trends Over 10 Years of Computational Thinking Research
}

\author{
Ulas Ilic \\ Pamukkale University, Turkey \\ Halil Ibrahim Haseski \\ Manisa Celal Bayar University, Turkey \\ Ufuk Tugtekin \\ Anadolu University, Turkey
}

\begin{abstract}
The current study aimed to review studies on computational thinking (CT) indexed in Web of Science (WOS) and ERIC databases. A thorough search in electronic databases revealed 96 studies on computational thinking which were published between 2006 and 2016 . Studies were exposed to a quantitative content analysis through using an article control form developed by the researchers. Studies were summarized under several themes including the research purpose, design, methodology, sampling characteristics, data analysis, and main findings. The findings were reported using descriptive statistics to see the trends. It was observed that there was an increase in the number of CT studies in recent years, and these were mainly conducted in the field of computer sciences. In addition, CT studies were mostly published in journals in the field of Education and Instructional Technologies. Theoretical paradigm and literature review design were preferred more in previous studies. The most commonly used sampling method was the purposive sampling. It was also revealed that samples of previous CT studies were generally pre-college students. Written data collection tools and quantitative analysis were mostly used in reviewed papers. Findings mainly focused on CT skills. Based on current findings, recommendations and implications for further researches were provided.
\end{abstract}

Keywords: Computational thinking; Research trends; Content analysis; Problem solving

\section{Introduction}

Individuals take on several social roles within the rapid flow of daily life and need to fulfill a variety of responsibilities. Contemporary opportunities to access information increase the speed of production and sharing of information which both facilitates and accelerates such responsibilities. The intertwined social roles in such a hectic world complicate the problems of living together. This transition introduced a transformation in effective thinking and decisionmaking processes as well. Thus, Computational Thinking (CT) skills constitute an essential trait in actively resolving the problems contemporary individuals face (Denning, 2009; Guzdial, 2008; ISTE, 2016; Wing, Henderson, Hazzan, \& Cortina, 2005; Wing, 2006). 
The first definition attempts for CT became prominent in early 1900s, which were expressed within the context of algorithmic thinking processes and cognitive problem formulation (Denning, 2009). In 1996, the term CT was proposed by Papert (1996), followed by the studies of Jeannette Wing (2006). Then, it became a topic of popular interest in scientific circles gradually (Selby, 2014). Although there is not a universal consensus on CT frameworks in the literature, several definition attempts exist (Barr \& Stephenson, 2011; Grover \& Pea, 2013). For instance, Wing (2006) defined CT as a solution to real life problems through utilizing information technologies whenever necessary. In addition, Guzdial (2008) defined CT as a general problem-solving process based on abstraction, analysis, automation, and modeling. ISTE and CSTA (2011) defined CT as a set of skills that includes the processes of analyzing an encountered problem, logical organization of the data obtained through such analyses, expression of the organized data as models, determination of the solutions through algorithmic thinking, selection of the most adequate ones among the determined solutions and the transfer of the selected solutions to new cases. Above definitions demonstrate that CT was based on a systematic approach to solve complex problems. Since complex problem solving skills could be employed in several fields, it was mentioned in the literature that CT could be effective in the fields of archeology, astronomy, linguistics, computer sciences, mathematics, geography, pharmacy and medicine, education, economics, basic sciences, journalism, meteorology, engineering, social sciences and arts (Lu \& Fletcher, 2009; Riley \& Hunt, 2014; Sorguç, 2013; Srihari \& Singer, 2014; Wing, 2006).

In this regard, educational researchers have also conducted studies to understand the CTrelated constructs better. Accordingly, it was observed that several topics such as programming instruction (Denner, Werner, Campe, \& Ortiz, 2014; Pellas \& Peroutseas, 2016), computer software (Haseski, illic, \& Tugtekin, 2017; Tahy, 2016; Weintrop, Holbert, Horn, \& Wilensky, 2016) and robots (Berland \& Wilensky, 2015; Bers, 2010; Kafai \& Burke, 2013) were investigated with respect to $\mathrm{CT}$. Furthermore, there are also studies in the literature on the integration of CT to educational contexts (Israel, Pearson, Tapia, Wherfel, \& Reese, 2015; Olabe, Basogain, \& Basogain, 2015) and the design of CT-oriented curricula (Bers, Flannery, Kazakoff \& Sullivan, 2014; Manson \& Olsen, 2010). Additionally, it was observed that different methodologies were used up to the experimental design from the literature review, and qualitative and quantitative data collection techniques were used on several sample groups (Denning, 2012; Farris \& Sengupta, 2016; Pellas \& Peroutseas, 2016).

Although there are several studies in the literature that addressed different aspects of CT, there is not a comprehensive study to reflect the research trends of such studies. In this regard, content analyses on contemporary educational technologies can guide scholars to plan their further researches accordingly (Akbulut \& Cardak, 2012; Goktas et al., 2012; Kucuk, Aydemir, Yildirim, Arpacik, \& Goktas, 2013; Shih, Feng, \& Tsai, 2008). In other words, scrutinizing the $\mathrm{CT}$ research trends through a comprehensive content analysis can contribute significantly to shaping new directions for future studies in the field. Thus, the aim of the current study was to review scientific papers published in the journals indexed by Web of Science (WOS) and ERIC databases in the last ten years (i.e., from 2006 to 2016), and to address the research trends through considering different variables regarding the study features. In the direction of above-mentioned main purpose of this study, more specifically, annual distribution of CT studies, distribution with regard to indices, journals and citation counts, objectives of the studies, preferred research paradigm and designs (i.e., sampling methods and sample size, target audience, variables of interest, data collection instruments, data analysis techniques) and main findings were aimed to determine. 


\section{Methodology}

\section{Research Model}

Comprehensive search on electronic databases was conducted through frequently used keywords in the CT literature. Accessed publications were examined through the "Computational Thinking Article Control Form (CTACF)" developed by the researchers. The data were analyzed through content analysis, which involved comparison, classification and association techniques to analyze obtained data (Bauer, 2000; Fraenkel \& Wallen, 2000; Weber, 1998).

\section{Search Strategies}

Search was conducted in WOS and ERIC databases. "Computational thinking" keyword was used in topic section for WOS search. Besides, article including titles "computational" and "thinking" words were included as well. Similarly, the keywords "computational" and "thinking" were used to search in the ERIC database for publications that do not have access to the full text, a search has been made from the journal's website. In addition, the corresponding author and other authors were contacted for such studies. As a result of the search made on December 10-11, 2016, a total of 271 articles were reached, of which 101 were from the WOS and 170 ERIC databases.

\section{Inclusion/Exclusion Criteria}

As in all systematic review studies, several inclusion-exclusion criteria have been identified in this study as well. To be included for analysis, a study has to meet the following criteria:

- Be published in a journal article

- $\quad$ Be published earlier than 2017

- Have access to the full text

- Address the CT subject

The first criterion was chosen to reach high quality publications. Thus, publications such as conference proceedings and book reviews were excluded. These types of documents were omitted due to the unclear peer review process. Unpublished dissertations were excluded as well. For the year as second criterion no start point was set, but the search results confirmed that Wing's (2006) work was considered to be a milestone. Hence, starting from 2006, publications were included in the study until 2017. On the other hand, some early publishing journals released 2017 issues at the search date. However, it was decided to exclude the inclusion of only a certain part of the year 2017, considering that it might affect the trends at year's end. Another criterion was to access the full text of the studies. This decision was made due to impossibility to review the studies from only the abstracts of non-full texts. The final criterion was the choice of topic. As CT addresses a wide area, the search results have revealed studies from several fields. Studies including topics such as Mathematical computational theories and computational models were excluded from the analysis. Failure to meet any of these 4 criteria led to exclusion of the study. 


\section{Data Collection Instrument}

The CTACF was developed as the data collection instrument to ensure study validity and reliability. Validity is considered as the unbiased observation of the studied phenomenon as is (Kirk \& Miller, 1986), while reliability is considered as a reproducibility of research findings (Merriam \& Tisdell, 2015). For this purpose, the CTACF form was employed. During the development of the CTACF, the criteria that the articles should comply were determined initially. The criteria were based on the research questions in the present study and the previous content analyses conducted on educational technologies (Akbulut \& Cardak, 2012; Goktas et al., 2012; Kucuk et al., 2013; Shih et al., 2008). The form was finalized after obtaining the contextual approval of three measurement and assessment experts. The criteria included in the CTACF and the options provided for these criteria are presented in Table 1.

Table 1. CTACF Criteria and Criteria Options

\begin{tabular}{ll}
\hline Criteria & Options \\
\hline $\begin{array}{l}\text { Indexes } \\
\text { Journal Titles } \\
\text { Years } \\
\text { Citations }\end{array}$ & SSCl, other \\
$\begin{array}{l}\text { Average citations } \\
\text { Purpose }\end{array}$ & 2006...2016 \\
Paradigm & Citations / (2017 - year of publication) \\
Research Design & Theoretical, Qualitative, Quantitative, etc. \\
Sampling method & Survey, Experimental, Case study, etc. \\
$\begin{array}{l}\text { Sample type } \\
\text { Sample size }\end{array}$ & Purposive, random, criterion, etc. \\
Data Collection Method & Primary school, middle school, high school, etc. \\
Variables of interest & 0-100, 101-200, 201-300, etc. \\
Data analysis & Survey, interview, observation, etc. \\
Main findings & Qualitative, Quantitative, etc. \\
\hline
\end{tabular}

\section{Data Analysis Process}

A spreadsheet software was used for the content analysis. Primarily, the topics in the developed CTACF were entered into the software and then, the properties of the selected articles related to these topics were written in the related columns. The properties that were not related to the specified topics were moved to related columns. In the next step, the information entered in the software was evaluated through descriptive statistics (i.e., frequencies and percentages). Descriptive statistics was selected since it provides the ability to order and summarize the study data (Lomax \& Hahs-Vaughn, 2012). Furthermore, relevant statistics were utilized to determine the trends on an annual basis. The abovementioned steps were conducted by a faculty member and two PhD candidates who had publications on CT. In order to provide coding consistency, all publications were reviewed by two researchers independently. In addition, coded data in spreadsheet by two researchers was analyzed for each main criteria using a statistical software. Inter-rater agreement between coders was $\mathrm{K}=$ .79 for methodology titles, $\mathrm{k}=.89$ for main subject and $\mathrm{k}=.83$ for variables and main findings. Thus, agreement values of the current study are substantial and above. Besides, 
faculty member obtained the consensus for discrepancies. Thus, inconsistencies in the content analysis were avoided. As the supervisor of the study, the faculty member assumed the role of leadership and ensured the management of the process. For studies with ambiguous methodological steps with regard to research paradigm, design and data analysis techniques, a consensus was established through further discussion on the methodology of these studies.

\section{Limitations}

One of the limitations of review studies is the impossibility to examine all the literature (Van der Kleij, Feskens, \& Eggen, 2015). In this context, WOS and ERIC databases were utilized in the study due to their importance and scope. Search results are limited to articles published in 2006-2016. Besides, developed form used for evaluation of the studies is another limitation of this research.

\section{Findings}

\section{Distributions and Trends Based on Years, Indexes and Journals}

As seen in the Figure 1, among the reviewed publications, 9 were published in $2013(9.3 \%), 17$ in 2014 (17.7\%), 25 in 2015 (26.0\%) and 29 were published in 2016 (30.2\%). It was observed that the number of articles published in the last 4 years was 80 (83.2\%). It was identified that the total number of publications between 2006 and 2013 was only $16(16.8 \%)$. That is, the number of studies on CT that were first published in 2006 was stagnant until 2013, but increased since 2013.

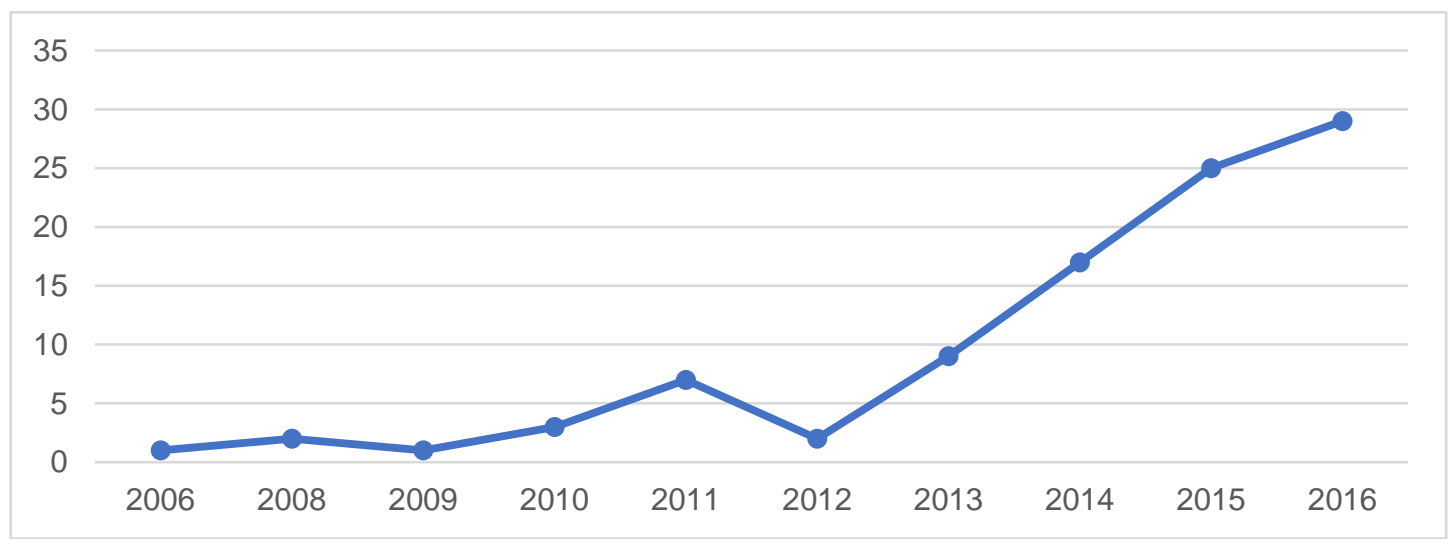

Figure 1. Distribution of Studies Conducted on CT Varied Based on the Year of Publication

The analysis revealed that $16(16.6 \%)$ out of the 96 CT studies were published in 60 different journals indexed in WOS, and 80 (83.4\%) were published in other indices. The largest number of publications was in ACM Transactions on Computing Education $(f=11)$. This journal was followed by Revista de Educación a Distancia $(f=8)$, Journal of Educational Computing Research $(f=5)$, Computer Science Education $(f=4)$, and Computers \& Education, Journal of Research on Technology in Education and Journal of Science Education and Technology with 3 
publications each. It could be argued that these journals focused on computer sciences, education and technology, and this fact was effective in the high frequency of CT articles.

\section{Main Subject of Journals}

As seen in Table 2, articles on CT were published in 12 different types of publications. Among the mentioned journals, the leading number of journals were on Education and Instructional Technologies $(f=39)$. These journals were followed by journals published in the fields of Formal and Informal Education $(f=26)$ and Computer Sciences and Technology $(f=16)$.

Table 2. Subject Fields of Journals Where Studies on CT Were Published

\begin{tabular}{lc}
\hline Journal Subject Fields & $f$ \\
\hline 1. Education and Instruction Technologies & 47 \\
2. Formal and Informal Education & 18 \\
Mathematics Education & 4 \\
Education and Education Theory & 3 \\
Teacher Training & 2 \\
Educational Philosophy & 2 \\
Pedagogy & 2 \\
Special Education & 1 \\
Preschool Education & 1 \\
Education Administration & 1 \\
Learning & 1 \\
Public Education & 1 \\
3. Computer Sciences and Technology & 16 \\
4. Biology & 5 \\
5. Engineering & 2 \\
6. Robotics & 2 \\
7. Linguistics & 1 \\
8. Biochemistry & 1 \\
9. Aeronautics & 1 \\
10. Journalism & 1 \\
11. Ecosystems & 1 \\
12. Politics & 1 \\
\hline & 1 \\
\hline
\end{tabular}

\section{Highly Cited Papers and Annual Citations}

Both total number of citations $(f=1615)$ and mean number of citations $(f=16.8)$ to CT papers were quite high. Among the publications examined, it was determined that 17 papers (17.7\%) were cited more than the average citations in the sample. Among these publications, a study by Wing (2006) who was considered as a pioneer in the CT field, was the most cited paper $(f=$ 437). Furthermore, it could be argued that the average number of citations based on the years of the study was very high as well $(f=4.44)$. It was determined that $25(26 \%)$ papers were cited more than the aforementioned average. Based on average citations per year, the study by Grover and Pea (2013) was cited the most $(f=62)$. This study was followed by Wing's (2006) paper $(f=48.5)$. On the other hand, 16 papers were yet to be cited as of March 13, 2017 
(16.7\%), when the current content analysis was completed. The fact that most of these papers $(56.2 \%)$ were published during recent years can be the reason for the lack of citations. The fact that 9 papers were published in 2013 (9.3\%), 17 in 2014 (17.7\%), 25 in 2015 (26.0\%) and 29 in $2016(30.2 \%)$ supports the above assumption. Furthermore, while the number of papers published in the last 4 years was 80 (83.2\%), the number of papers published between 2006 and 2013 was only $16(16.8 \%)$. It could be argued that although the publication of the studies on CT started on 2006, there were fewer number of papers published until 2013, when the number of publications increased considerably.

\section{Study Purposes}

The analysis of the objectives of the CT studies revealed the themes of "CT in the context of education" $(f=44)$, "CT in the context of technology $(f=36)$ ", "rendering CT comprehensible" $(f=7)$, respectively. Analysis of the objectives demonstrated that majority of the studies were conducted under of the code of "development of CT skills with 3D modeling and programming" under the theme of "CT in the context of technology" $(f=22)$. In this regard, it could be argued that CT was usually studied within the context of computer sciences. On the other hand, it could be argued that the abovementioned finding does not fully support the assumption that CT is a skill that must be possessed by everyone for use in every aspect of daily life, in addition to being limited to the field of computer sciences. The second highfrequency objective $(f=17)$ was under the code of "development and significance of CT skills in the classroom environment (in classes and courses)" under the theme of "CT in education context". When the objectives of the investigated studies were analyzed based on the year of publication, it was observed that the theme of "rendering CT comprehensible" was scrutinized mostly between 2006 and 2016. The theme of "CT in daily life" was mostly addressed between 2008 and 2016, the theme of "CT in the context of technology" was mostly discussed between 2009 and 2016 and the theme of "CT in the context of education" was mostly scrutinized between 2010 and 2016.

\section{Study Paradigm}

Five different paradigms were used in the studies; theoretical $(f=38)$, qualitative $(f=23)$, quantitative $(f=20)$, mixed $(f=13)$ and design based $(f=1)$. On the other hand, the paradigm was not clearly stated in 7 quantitative studies, 3 mixed design studies and 7 qualitative studies. Furthermore, the paradigm of the design-based study was derived by the authors of the present study. The fundamental paradigm was not mentioned in 1 study. The distribution of paradigms in the sampled studies based on the year of publication is presented in Figure 2. 


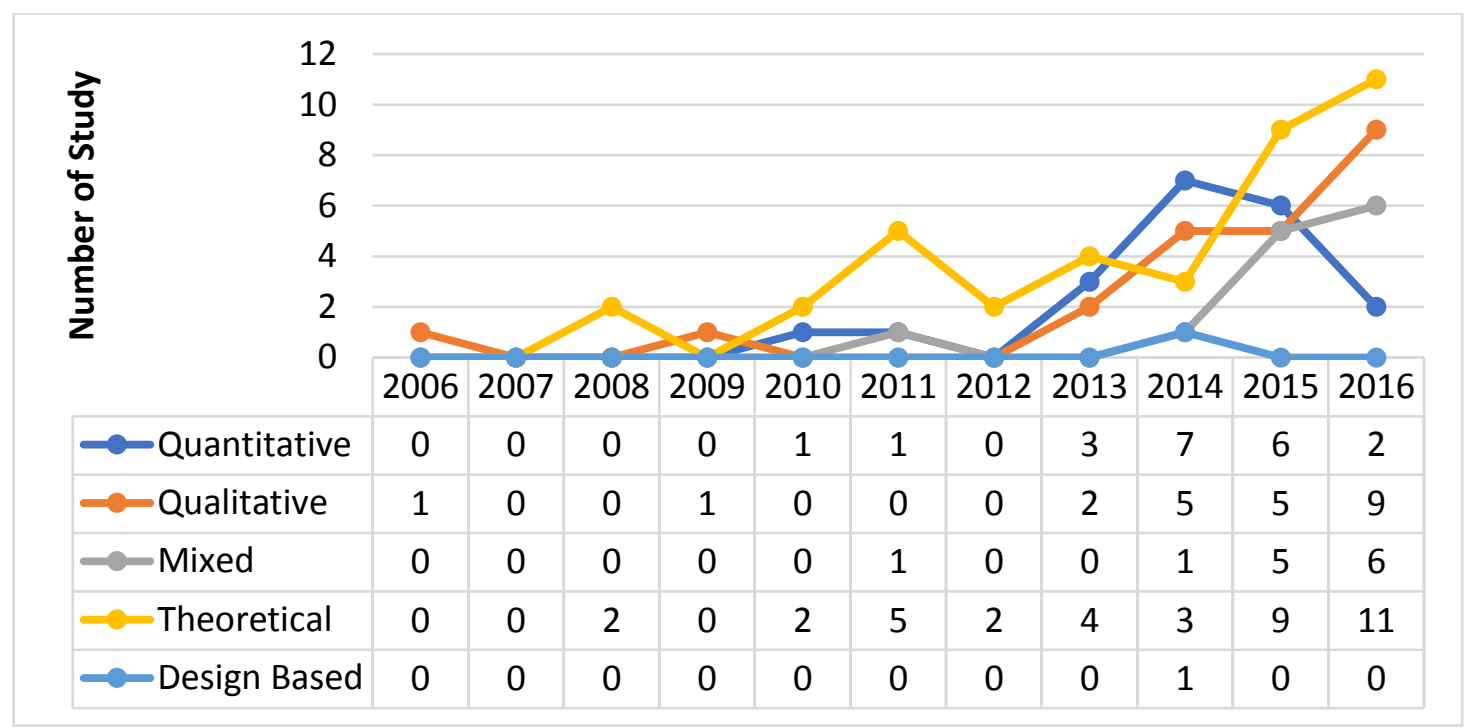

Figure 2. Distribution of Studies on CT in the Context of Study Paradigm by Years

As seen in Figure 2, studies were conducted within the scope of qualitative and theoretical paradigms between 2006 and 2009 and studies within the scope of quantitative paradigm were conducted after 2010. It was determined that the analyzed studies conducted between 2010 and 2016 benefited from quantitative, qualitative, mixed, theoretical and design-based research paradigms. The quantitative paradigm was most prominently utilized in $2014(f=7)$. However, it was noteworthy that the number of studies conducted with the quantitative paradigm by 2013 increased until 2014 and decreased in 2015. The number of studies conducted with the qualitative paradigm, on the other hand, exhibited especially by 2013. Similarly, it was noteworthy that the studies conducted based on the theoretical paradigm demonstrated an increase between 2014 and 2016.

\section{Study Methods}

The most preferred design was the literature review $(f=25)$ followed by experimental designs $(f=19)$ and case studies $(f=17)$. Further analyses revealed that 12 different designs were utilized. In 19 studies there was no mention of the research design. Among these studies, 16 research designs were identified by the authors of the current study. Analysis of the research designs utilized in studies on CT based on the year of publication demonstrated that one case study was conducted in 2006. From 2006 to 2010, it was observed that research designs such as survey model, literature review and case study were utilized in the reviewed studies. The first experimental design was used in 2011. From 2011 onwards, especially as the popularity of the $\mathrm{CT}$ began to increase, the number of studies conducted with quantitative design increased. In particular, analysis of the research designs of the studies conducted in 2014, 2015 and 2016 demonstrated that there was no descriptive study. Based on these findings, it was concluded that the trends in studies on CT was generally theoretical studies between 2006 and 2010, however, between 2011 and 2016, 12 different designs were preferred including case studies, literature review, survey model, experimental designs, descriptive studies, user centered design research, grounded theory, experience-based needs assessment, phenomenology, field research and documentary research, design-based research and three-pronged approach. 


\section{Sample Selection Methods, Sample Populations and Sample Size Based on the Paradigm}

The most commonly used sampling method was the purposive sampling $(f=25)$. This was followed by random sampling $(f=4)$, criterion sampling $(f=2)$, quota sampling $(f=1)$, cluster sampling $(f=1)$ and stratified sampling $(f=1)$. On the other hand, it was observed that 27 studies did not include a specific sampling method. In 36 studies there was no sampling.

Preferred samples mostly included primary education students $(f=58)$, followed by present and future stakeholders in education $(f=19)$, university students $(f=17)$ and other samples $(f$ $=5)$, respectively. Three studies did not mention the groups included in the sample. Furthermore, no sample group was used in 30 reviewed studies due to the preferred research design.

Analysis of sample groups based on the year of publication demonstrated that no sample group was selected between 2006 and 2008. It was noted that middle school students were included in the sample of one study conducted in 2009 for the first time among the reviewed 96 studies on CT. In studies conducted between 2010 and 2016, use of sample groups increased and primary education students, college students and other sample groups were included.

Table 3. Sample Sizes Based on Study Paradigms

\begin{tabular}{ccccccccc}
\hline \multirow{2}{*}{ Paradigm } & $\begin{array}{c}\text { Sample } \\
\text { Size }\end{array}$ & $f$ & Paradigm & $\begin{array}{c}\text { Sample } \\
\text { Size }\end{array}$ & $f$ & Paradigm & $\begin{array}{c}\text { Sample } \\
\text { Size }\end{array}$ & $f$ \\
\hline Quantitative & $0-100$ & 9 & Qualitative & $0-10$ & 3 & Mixed & $40-50$ & 2 \\
& $101-200$ & 2 & & $11-20$ & 2 & & $51-60$ & 5 \\
& $201-300$ & 2 & $30-40$ & 1 & & $61-70$ & 1 \\
& $301-400$ & 2 & $41-50$ & 3 & & $71-80$ & 1 \\
& $401-500$ & 2 & $51-60$ & 1 & & 81 and higher & 3 \\
501 and & 3 & 61 and & 1 & & & \\
higher & 3 & higher & 1 & & & \\
\hline
\end{tabular}

As indicated in Table 3, it was determined that studies with quantitative research design were mostly utilized a sample size of 0-100 $(f=9)$. Studies with a qualitative research design utilized a sample size of $0-50(f=9)$. It was observed that the majority $(75 \%)$ of the mixed-design studies were conducted with 80 or less subjects. On the other hand, it was determined that one study with design-based research design was conducted with 0-10 participants.

\section{Variable Trends}

As seen in Table 4, it was determined that the most addressed variable in studies on CT was CT itself $(f=43)$. It was observed that the most studied variables under the topic of CT were CT skills $(f=17)$, the structure of CT $(f=12)$, CT levels $(f=8)$ and CT achievements $(f=2)$, respectively. Furthermore, it was observed that the second most frequent variable tackled within the context of CT was personal traits $(f=31)$. Cognitive $(f=16)$ and affective traits $(f=$ 
15) of individuals were examined within the context of personal traits. It could be argued that the other variables shown in the table were studied in relatively lower number of papers.

The fact that the variables measured in the reviewed studies included 9 themes was a noteworthy finding. Thus, it could be argued that CT was a comprehensive field and a significant topic that was investigated under different contexts since 2006. On the other hand, it was determined that no variable was measured in 36 papers within the context of the present study.

Review of the distributions of the variables measured in the analyzed studies based on the year of publication demonstrated that the theme of CT was analyzed between 2006 and 2016, the theme of robotics was analyzed between 2010 and 2016, the theme of instructional strategies was analyzed only in 2011, the theme of personal traits was analyzed between 2011 and 2016, the theme of integration was scrutinized only in 2015, the themes of computer training and literacies were analyzed between 2015 and 2016 and other variables were scrutinized between 2011 and 2016.

Table 4. The Variables Scrutinized in Studies on CT

\begin{tabular}{lc}
\hline Variables & $\mathrm{f}$ \\
\hline CT & 43 \\
Personal Traits & 31 \\
Robotics & 4 \\
Programming & 3 \\
Integration & 2 \\
Computer training & 2 \\
Literacies & 2 \\
Instruction Strategies & 1 \\
Others & 10 \\
\hline
\end{tabular}

\section{Data Collection Tools}

As seen in Table 5, pen-and-paper data collection tools $(f=74)$, audio-visual data collection tools $(f=53)$ and the performance evaluations $(f=6)$ and literature reviews $(f=1)$ were utilized in the papers. It was determined that surveys $(f=28)$ and interviews $(f=28)$ were the most preferred data collection tools. Analysis of the quantities of preferred data collection tools demonstrated that multiple data collection tools were used in 43 studies whereas 17 studies resorted to single data collection tools. 35 studies utilized no data collection tool, and 1 paper did not mention the data collection technique utilized. 
Table 5. Data Collection Tools Utilized in Scientific Papers on CT

\begin{tabular}{lccc}
\hline \multicolumn{1}{c}{ Data Collection Tool } & $f$ & Data Collection Tool & $f$ \\
$\begin{array}{l}\text { 1. Written Data Collection } \\
\text { Tools }\end{array}$ & 28 & 2. Audio-Visual Data Collection Tools & \\
Survey & 19 & Interview & 28 \\
Achievement test/quiz & 7 & Observation & Virtual material/software and \\
Scale & 6 & activity records & 8 \\
Rubric & 4 & Video recordings & 3 \\
Reflection reports & 4 & 3. Performance Evaluation & 1 \\
Written documents & 3 & 4. Literature Review & 6 \\
Field notes & 3 & & 1 \\
Checklist & 1 & & 60 \\
Coding scheme & 74 & TOTAL & \\
TOTAL & \multicolumn{2}{l}{} \\
\hline
\end{tabular}

\section{Data Analysis Methods}

Quantitative analysis $(f=58)$, qualitative analysis $(f=32)$ and different approaches $(f=13)$ were used in reviewed papers. Furthermore, 23 papers were descriptive studies, which did not utilize any data analysis technique. In addition, 37 reviewed papers did not contain any information on the utilized data analysis technique.

In quantitative papers, parametric analysis techniques $(f=49)$ and nonparametric $(f=9)$ analysis techniques were used. Among the quantitative data analysis techniques, test $(f=16)$, ANOVA $(f=12)$, MANOVA $(f=4)$, regression $(f=4)$ and ANCOVA $(f=3)$ were the most frequent tests. Among the nonparametric techniques, Wilcoxon signed rank test $(f=3)$ and Pearson's Chi-square test $(f=3)$ were the most preferred ones. It was observed that 39 papers that used quantitative data analysis techniques were conducted to determine the difference between the variables, and 9 were conducted to determine the correlation between the variables.

Among the qualitative papers that were reviewed in the present study, it was observed that the most preferred analysis method was content analysis $(f=20)$. Content analysis was followed by descriptive analysis $(f=1)$, handwriting analysis and artifact-based interview analysis $(f=1)$. It was observed that content analysis was used extensively in qualitative studies. It could be argued that the reason for this finding was due to the necessity of providing a clear structure to the topic by examining CT in depth. Furthermore, the need for further studies to define the CT supports the tendency of the abovementioned analysis technique in qualitative studies.

The review of the studies conducted on CT revealed that quantitative data analysis techniques were utilized more when compared to qualitative data analysis techniques. It was also found that the number of studies that used multiple data analysis techniques was 37 and 24 studies 
used only one analysis technique. The number of studies that did not specify an analysis technique or that did not utilize an analysis technique was 35 . Among the reviewed studies, the authors of the present study deducted that 12 papers that did not specify an analysis technique utilized content analysis and 3 were descriptive studies.

When the data analysis techniques were examined based on the year of publication, it was observed that studies conducted with quantitative analyzes were published between 2010 and 2016. Among the reviewed quantitative researches, non-parametric analyzes were utilized between 2014 and 2016. Furthermore, when it is considered that advanced quantitative analyzes were utilized by 2015 , it is possible to argue that the variables considered in the studies on CT and thus, the quantitative analyses conducted have increased during recent years. On the other hand, among the reviewed studies, it was determined that the qualitative analysis methods were used between 2009 and 2016. Although it was observed that experimental studies on CT have been increasing during recent years, it is also noteworthy that the qualitative studies were conducted continuously starting on 2009.

\section{Main Study Findings}

Analysis of the main findings determined in scientific papers conducted on CT revealed the themes that are presented in Table 6. As seen in Table 6, the main findings of the studies on CT shaped around 6 themes. Based on these themes, the most frequent finding was about the development of CT skills $(f=43)$. Related findings were about the position of CT in curricula and education $(f=24)$ and other fields where CT is effective $(f=10)$ respectively. Based on these findings, it could be argued that although there were studies on the development of CT skills and the position of CT in education among the scientific studies conducted on the topic, there were relatively smaller number of studies on the reflections of CT on other fields and assessment of CT. However, it was observed that the findings obtained in general had positive results in the context of $\mathrm{CT}$.

Table 6. Main Findings Determined in Scientific Papers Conducted on CT

\begin{tabular}{lc}
\hline \multicolumn{1}{c}{ Main Findings in Studies Conducted on CT } & $f$ \\
\hline 1. Findings on CT skills & 43 \\
Programming instruction improves CT skills & 13 \\
Computer software improve CT skills & 8 \\
CT skills are significant in problem solving & 6 \\
Robotics improve CT skills & 3 \\
Visual drawings improve CT skills & 2 \\
Storytelling improves CT skills & 1 \\
IT instruction improves CT skills & 1 \\
Courses improve CT skills & 1 \\
Time process is significant in development of CT skills & 1 \\
Other ways/applications that support CT skills & 9
\end{tabular}

2. Findings on the position of CT in curricula and education 24

CT should be integrated to education 9

Curricula should be reorganized based on CT skills 7

$\mathrm{CT}$ is useful in courses 5

CT should be included in teacher training 3 
3. Findings on other fields where $\mathrm{CT}$ is effective 10

4. Findings on structures that are related to $\mathrm{CT} \quad 6$

5. Findings on the evaluation of CT 5

6. Other findings 14

Findings of the review conducted on the studies on CT demonstrated that findings on CT skills were started to be obtained after 2008. It was determined that the number of studies that provide findings on the integration of CT into the curriculum and the status of CT in education have increased with an accelerating momentum from 2013 onwards, as seen in Figure 3. On the other hand, it was observed that studies with findings about the assessment of CT were predominantly included in the literature starting from 2015. Furthermore, it was observed that the studies that provided other findings related to the CT have started to be conducted from 2012 onwards. In addition, a majority (90\%) of studies with findings on other areas where CT is effective were performed after 2013.

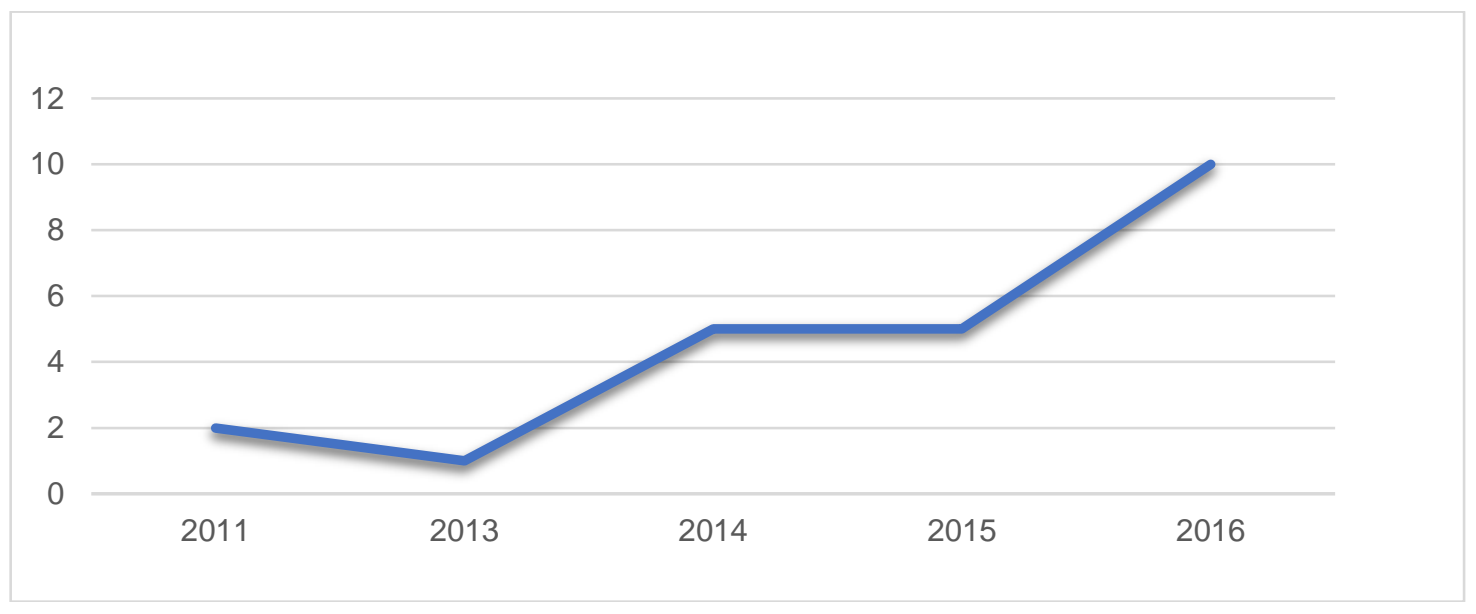

Figure 3. Distribution of Main Findings of Studies on CT based on the Year of Publication

\section{Conclusion and Recommendations for Future Research}

In the present study, 96 studies on CT were reviewed based on the journal that published these papers the most, the highest citations and the number of citations per year, study objectives, paradigms, methodologies and methodology trends, sample size, data collection tools, variables of interest, data analysis and main findings. We believe that the findings obtained in the present study might be useful for explaining current trends on CT and in guiding future studies.

Studies that started with a paper by Wing (2006), which drew attention to the concept of CT in the 21st century, demonstrated a significant increase since 2013. This may be related to the popularity of the concept and awareness about its significance. Especially during recent years, the focus on CT by pioneering field organizations such as Google for Education (2015) and ISTE (2016) supports the abovementioned finding. Based on the findings of the present study, the majority of the reviewed studies were published in journals that were not $\mathrm{SCl} / \mathrm{SSCl}$ indexed. However, the increase in the number of publications indexed in the abovementioned indexes during recent years could be related to the increasing significance of the topic (Lim, 2015; 
Mohaghegh \& McCauley, 2016; Selby, 2014; Weintrop, 2016) and publication of higher-quality papers. Furthermore, considering that reviewed studies were published in 60 different journals covering a wide range of fields such as formal and informal education, linguistics, biology, biochemistry, engineering, aviation, robotics, computer sciences and technology, journalism, ecosystem and politics, the extent of the field addressed by CT could be better understood.

In addition to the scope of the studies, the number of citations these papers received was scrutinized to determine their effects on the literature (Akbulut \& Cardak, 2012; Garfield, 1972; Shih et al., 2008). Thus, the present study findings also demonstrated that the number of citations to these papers were high. Accordingly, it could be concluded that the concept of CT attracted the attention of scholars. It could be stated that Wing's (2006) and Grover and Pea's (2013) studies received the highest number of annual citations. In other words, the impact of such papers with the highest number of stations is also significant as these papers could assist researchers as models (Shih et al., 2008).

$\mathrm{CT}$ is a competency that is required for all fields, not only for computer sciences (Willamson, 2016; Wing et al., 2005). However, based on the findings of the current study, majority of the studies on CT in the literature concentrated on education and technology. Furthermore, study findings demonstrated that CT was mostly discussed based on computer technologies (Israel et al., 2015; Kim, Kim, \& Kim, 2013; Pellas \& Peroutseas, 2016). It was considered that this finding was due to the low level of perception of the significance of CT in other fields. Similar to this finding, it was determined that the concept of CT was started to be discussed and investigated in the context of education since 2010. This implies that the significance of CT in education was only recently realized. First studies on CT were conducted to clearly define the concept (Aho, 2012; Wing, 2008), followed by studies on the technology (Bers et al., 2014; Berland \& Wilensky, 2015) and education (Shell \& Soh, 2013; Wilkerson-Jerde, 2014), respectively. Based on this trend, it is possible to predict that CT skills would be discussed and significant in the field of education and its significance would increase in the future as well.

It was determined that the highest number of studies were theoretical, followed by qualitative, quantitative and mixed-design studies, respectively. Except the theoretical studies, these results were consistent with the findings in the literature (Hew, Kale, \& Kim, 2007; Hranstinski \& Keller, 2007; Kucuk et al., 2013; Ross, Morrison, \& Lowther, 2010).It could be argued that the high number of theoretical studies was due to the need for a more comprehensive understanding of the $\mathrm{CT}$, which is a relatively novel concept.

While the studies were mostly based on theoretical and qualitative paradigm during the initial years, quantitative studies were also conducted after 2010. Starting with 2014, it was considered that the theoretical studies increased again due to renewed popularity of CT (Selby, 2014) and the theoretical contradictions in the field (Aho, 2012; Denning, 2012; Grover \& Pea, 2013; Voogt, Fisser, Good, Mishra, \& Yadav, 2015; Wing, 2008; Xu \&Tu, 2011). On the other hand, it was interesting that the study paradigm was not explicitly stated in 17 reviewed papers. The research method is important to better understand the results and the contribution of the study to the literature (López, Valenzuela, Nussbaum, \& Tsai, 2015). Thus, it was considered that the studies that lacked explicit statements on the study paradigm would have limited contributions both to the present study and to the literature.

Study findings demonstrated that literature reviews, experimental designs and case studies were predominantly preferred by the scholars. When it is considered that the underlying paradigm is effective on the determination of the research design (Cresswell, 2013), it could be 
observed that the abovementioned finding was consistent with the choice of theoretical studies for the study paradigm. Furthermore, there are also studies in the literature which reported that case studies (Kucuk et al., 2013) and experimental studies (Shih et al., 2008) were also frequently preferred. However, no experimental study was conducted until 2011. Experimental studies, however, are distinguished from other research methods since they are the only method where the effects of a variable in an event could be observed (Fraenkel \& Wallen, 2006). This finding was consistent with the fact that the concept of CT became significant in education since 2010 and became the topic of educational research only then. In addition, it could be argued that the number of descriptive studies that were conducted on CT with the survey model, which establishes the present conditions of large masses, was not adequate. As mentioned in the section about main findings of the reviewed papers, there were higher numbers of theoretical studies during the initial years of research, while this number decreased after 2014. Parallel to the findings on the study paradigm, it was observed that the research design was not clearly identified in 15 reviewed studies. This was considered to have reduced the repeatability of the studies in similar contexts and restricted the contributions of the studies to the literature.

With respect to sample populations, study findings demonstrated that studies on CT focused mostly on primary education students. This sample group was followed by present and future stakeholders in education and college students. This finding was not consistent with the findings of other studies in the literature which claimed that the studies were mostly conducted with college students (Akbulut \& Cardak, 2012; Goktas et al., 2012; Hwang \& Tsai, 2011; Kucuk et al., 2013). On the other hand, Shih et al. (2008) reported similar sample populations. When it is considered that college students were generally preferred in studies on education technologies due to easy access (Akbulut \& Cardak, 2012; Goktas, 2012; Kucuk et al. 2013), it could be argued that studies on CT were conducted on different target groups including college students. It could be stated that since CT skills are particularly important and desirable for all individuals (Cecilia Martinez \& Emilia Echeveste, 2015; Wing et al., 2005), precollege students were included in samples of studies on CT extensively. Until 2010, there were no studies on CT conducted with university students. After 2010, studies that investigated different sample groups were conducted. Based on this finding, it could be argued that the studies conducted on CT since 2010 were conducted with different sample groups using various designs. On the other hand, the findings on sample selection methods demonstrated that the purposive sampling method was the most used method. This finding was consistent with the results of previous studies in the literature (Goktas et al., 2012; Kucuk et al., 2013; Shih et al., 2008; Simsek et al., 2009). It was considered that the ease of the method was effective on the preference of purposive sampling in reviewed studies (Creswell \& Poth, 2017; Fraenkel \& Wallen, 2000; Patton, 2014; Willis, 2008).

Analysis of the findings based on data collection tools demonstrated that survey and interview methods were the most frequently used data collection instruments. This finding was similar to the findings of other researches in the literature (Goktas et al., 2012; Hew et al., 2007; Simsek et al., 2009). Surveys might be preferred due to their easy and inexpensive nature (Baker, 2003; Buyukozturk, Kilic Cakmak, Akgun, Karadeniz, \& Demirel, 2009). Interviews were preferred because they are among the data collection tools used to obtain in-depth information in qualitative studies (Flick, 2008; Marshall \& Rossman, 2014; Merriam \& Tisdell, 2015; Patton, 2014). On the other hand, it is observed in the literature that there is a need for valid and reliable scales specific to $\mathrm{CT}$. This fact also indicates the present lack of measurement tools on CT parallel to the disagreements on the dimensions of the CT. 
It was observed that the variables of robotics (Sullivan \& Heffernan, 2016), literacy (DeSchryver \& Yadav, 2015), instructional strategies (Miller \& Settle, 2011), computer education (Snodgrass, Israel, \& Reese, 2016), integration (Israel et al., 2015), programming (Pellas \& Peroutseas, 2016) and cognitive features (Psycharis, 2016) were scrutinized in CT studies. Furthermore, the study of these variables indicated the significance and the potential of CT in the field of education. Analysis of the trends in these variables demonstrated that as the robotics achieved significance in the field of education (Bers, 2010), it was used as a variable in CT studies since 2010 (Bers et al., 2014; Sullivan \& Heffernan, 2016). Similarly, programming variable have been used since 2014 (Werner, Denner, \& Campe, 2015). However, the fact that studies utilizing computer education and instructional strategies variables, which are significant in education, were conducted after 2011 demonstrated that the awareness for the significance of the subject matter in education is rather new. Furthermore, it was observed that the number of above mentioned studies were very limited. Only 4 studies that included the variables of integration and computer education were found (Espino Espino \& Gonzalez Gonzalez, 2015; Israel et al., 2015; Olabe et al., 2015; Snodgrass et al., 2016), and there was only one study that investigated the instructional strategies (Millet \& Settle, 2011).

It was determined that parametric analysis techniques and content analysis techniques were the most frequently used data analysis methods in the reviewed studies on CT. The fact that parametric analyzes were mostly used in quantitative studies and content analysis were the most frequently used data analysis method in qualitative studies was similar to the findings of other studies in the literature (Goktas et al., 2012; Hsieh \& Shannon, 2005; Kucuk et al., 2013; Simsek et al., 2009). Furthermore, more than one analytical technique was used in the majority of the studies reviewed in the current research. The employment of more than one analytical technique could be related to the selection of adequate analytical technique for the related research questions (López, Valenzuela, Nussbaum, \& Tsai, 2015).In this context, the increasing trend in empirical studies since 2010 was also observed in the quantitative data analysis techniques. It was observed that advanced quantitative analysis techniques were utilized in studies on CT conducted since 2015. Similarly, parallel to the limitation in the number of scale studies that focused on the measurement of CT skills, it was observed that no structural model was determined between the analyzed variables. It could be argued that the ongoing debate on CT and the continuous lack of consensus about the conceptual disagreements on CT could be due to utilization of advanced data analysis techniques which can led to widespread impact. This suggests that the debate on CT would continue in the near future. On the other hand, it was determined that the data analysis method was not explicitly specified in certain CT studies. This was in contrast with the view that the data analysis process should be mentioned clearly in all researches (Arriaza, Nedjat-Haiem, Lee, \& Martin, 2015; López, Valenzuela, Nussbaum, \& Tsai, 2015).

Study findings are one of the most important sections in a research and it is therefore extremely important to express findings in a study clearly (Elliott et al., 1999; Hesse-Biber, 2010; Spencer et al., 2003). It was observed that adequate care was taken to express study findings in the reviewed papers. The main findings of the reviewed studies primarily included findings about CT skills. Study findings included elements that improved CT skills such as programming instruction (Olabe et al., 2015; Pellas \& Peroutseas, 2016; Perez \& Roig-Vila, 2015; Repenning et al., 2014; Wang, Wang, \& Liu, 2014), robotics (Bers, 2010; Sullivan \& Heffernan, 2016) and computer programs (loannidou, Repenning, \& Webb, 2009; MorenoLeón, Robles, \& Román-González, 2015; Repenning et al., 2015; Weintrop et al., 2016). It was observed that these studies were conducted since the beginning of the related literature. On the other hand, studies on the integration of CT into the curriculum and the studies on the 
significance of CT in education were started to be conducted on 2013. However, these studies included significant findings such as the integration of CT in education (Israel et al., 2015; Navlakha \& Bar, 2016, Voogt et al., 2015; Yadav, Hong, \& Stephenson, 2016), reorganization of the curriculum based on CT skills (Grover, Pea, \& Cooper, 2015; Jun, Han, Kim, \& Lee, 2014; Vallance \& Towndrow, 2016; Zapata-Ros, 2015) and the requirement of including CT in teacher training (Yadav, Mayfield, Zhou, Hambrusch, \& Korb, 2014, Yadav et al., 2016). However, it is important to understand and assess the constructs associated with CT in order to integrate this skill effectively into education. Thus, it is worth noting that the quantity of the studies that establish the correlation between the abovementioned variables and CT (Aho, 2012; DeSchryver \& Yadav, 2015; Jenkins, 2015; Park \& Jeon, 2015) and shed a light on active assessment of CT (Manson \& Olsen, 2010) is very limited. On the contrary, the fact that the studies on the topic has been increasing in recent years could be an evidence for the gradually improving awareness on the subject matter.

The increasing number of publications and citations in the period between 2006 and the present revealed that the $\mathrm{CT}$ is a subject that attracted the interest of scholars and became increasingly popular in scientific circles. Although different studies were conducted with different groups of participants in different contexts regarding $\mathrm{CT}$, it was considered that future studies should be conducted on CT since there are unclear aspects related to the subject matter. Thus, any future studies, including theoretical studies, could contribute to the literature. The following are recommended for future researches on $\mathrm{CT}$ :

- Studies could be conducted in the future to integrate CT into the classroom environment and to determine the pedagogical skills, instructional and learning strategies that educators should possess.

- Future design-based studies could enable the development of in-classroom activities and virtual media applications in educational institutions to acquire CT skills.

- The quality of activities and applications related to the acquisition of CT skills at schools can be improved with action researches.

- Further qualitative researches could be conducted with higher number of participants to explore in depth the current views and the status of different population on CT.

- Future empirical studies could be conducted with different target audiences to enable the acquisition of $\mathrm{CT}$ skills.

- Further studies could be conducted to determine the status of different groups in the society such as preschool age children, graduate students, children with disabilities, gifted students, elderly, academicians, and adults in various professions.

- Studies that aim to develop data collection tools such as valid and reliable scales, surveys and achievement tests that would measure CT more effectively could be conducted.

- The structure of the CT concept could be clarified using advanced statistics such as regression, PATH analysis and Structural Equation Modeling to see the interrelationships among relevant $\mathrm{CT}$ constructs.

- Future studies that would investigate the impact of CT on daily life, its practical uses and the acquisition of CT skills could be conducted. 
- Future studies that would investigate the effect and significance of CT on different professions could be conducted.

- Similar and periodic trend studies could be conducted to re-determine the future trends in the field.

- Clear and explicit presentation of methodological information such as the study paradigm, research design and the data analysis technique would improve the validity and reliability of future studies and increase their contribution to the literature.

Future studies and activities that would be conducted based on the above recommendations can make it possible to comprehend the concept of CT better and allow CT to adopt a structure that could be used in daily life by all groups in the society.

\section{References}

Aho, A. V. (2012). Computation and computational thinking. The Computer Journal, 55(7), 832835. https://doi.org/10.1093/comjnl/bxs074

Akbulut, Y. \& Cardak, C. S. (2012). Adaptive educational hypermedia accommodating learning styles: A content analysis of publications from 2000 to 2011. Computers \& Education, 58(2), 835-842. https://doi.org/10.1016/j.compedu.2011.10.008

Baker, M. J. (2003). Data collection- questionnaire design. The Marketing Review, 3(3), 343370. https://doi.org/10.1362/146934703322383507

Barr, V. \& Stephenson, C. (2011). Bringing computational thinking to K-12: What is Involved and what is the role of the computer science education community? ACM Inroads, 2(1), 48-54. https://doi.org/10.1145/1929887.1929905

Bauer, M.W. (2000). Classic content analysis: A review. In M.W. Bauer, \& G. Gaskell (Eds.), Qualitative researching with text, image and sound: A practical handbook (pp. 131-151). London: Sage.

Berland, M. \& Wilensky, U. (2015). Comparing virtual and physical robotics environments for supporting complex systems and computational thinking. Journal of Science Education and Technology, 24(5), 628-647. https://doi.org/10.1007/s10956-015-9552-x

Bers, M. U. (2010). The TangibleK robotics program: Applied computational thinking for young children. Early Childhood Research \& Practice, 12(2).

Bers, M. U., Flannery, L., Kazakoff, E. R., \& Sullivan, A. (2014). Computational thinking and tinkering: Exploration of an early childhood robotics curriculum. Computers \& Education, 72, 145-157. https://doi.org/10.1016/j.compedu.2013.10.020

Buyukozturk, S., Kilic Cakmak, E., Akgun, O. E., Karadeniz, S., \& Demirel, F. (2009). Bilimsel araştirma yontemleri. Ankara: Pegem Akademi.

Cecilia Martinez, M. \& Emilia Echeveste, M. (2015). Primary and secondary school students' representation about computer sciences and their job. RED-Revista De Educacion A Distancia, (46).

Creswell, J. W. (2013). Research design: Qualitative, quantitative, and mixed methods approaches. Thousand Oaks, CA: Sage. 
Creswell, J. W. \& Poth, C. N. (2017). Qualitative inquiry and research design: Choosing among five approaches (4th ed.). USA: Sage Publications.

Denner, J., Werner, L., Campe, S., \& Ortiz, E. (2014). Pair programming: Under what conditions is it advantageous for middle school students? Journal of Research on Technology in Education, 46(3), 277-296. https://doi.org/10.1080/15391523.2014.888272

Denning, P. J. (2009). The profession of IT beyond computational thinking. Communications of The ACM, 52(6), 28-30. https://doi.org/10.1145/1516046.1516054

Denning, P. J. (2012). Reflections on a symposium on computation. The Computer Journal, 55(7), 799-802. https://doi.org/10.1093/comjnl/bxs064

DeSchryver, M. D. \& Yadav, A. (2015). Creative and computational thinking in the context of new literacies: Working with teachers to scaffold complex technology-mediated approaches to teaching and learning. Journal of Technology and Teacher Education, 23(3), 411-431.

Espino Espino, E. E., \& Gonzalez Gonzalez, C. S. (2015). A study on gender differences in the skills and educational strategies for the development of computational thinking. REDRevista De Educacion A Distancia, (46).

Farris, A. V. \& Sengupta, P. (2016). Democratizing children's computation: Learning computational science as aesthetic experience. Educational Theory, 66(1-2), 279-296. https://doi.org/10.1111/edth.12168

Flick, U. (2008). Designing qualitative research. London: Sage.

Fraenkel, J. R. \& Wallen, N. (2000). How to design and evaluate research in education (4th ed.). New York: McGraw-Hill.

Garfield, E. (1972). Citation analysis as a tool in journal evaluation. Science, 178(4060), 471479.

Goktas, Y., Kucuk, S., Aydemir, M., Telli, E., Arpacik, O., Yildirim, G., \& Reisoglu, I. (2012). Educational technology research trends in Turkey: A content analysis of the 2000-2009 decade. Educational Sciences: Theory and Practice, 12(1), 191-199.

Google for Education (2015). Exploring computational thinking. Retrieved on March 31, 2017, from https://edu.google.com/resources/programs/exploring-computational-thinking/

Grover, S. \& Pea, R. (2013). Computational thinking in K-12: A review of the state of the field. Educational Researcher, 42(1), 38-43. https://doi.org/10.3102/0013189X12463051

Grover, S., Pea, R., \& Cooper, S. (2015). Designing for deeper learning in a blended computer science course for middle school students. Computer Science Education, 25(2), 199-237. https://doi.org/10.1080/08993408.2015.1033142

Guzdial, M. (2008). Education paving the way for computational thinking. Communications of The ACM, 51(8), 25-27. https://doi.org/10.1145/1378704.1378713

Haseski, H. İ., ilic, U., \& Tugtekin, U. (2017). Computational thinking in educational digital games: An assessment tool proposal. In H. Ozcinar, G. Wong \& H.T. Ozturk (Eds.), Teaching computational thinking in primary education (pp. 256-287). Hershey, PA: IGI Global. 
Hew, K. F., Kale, U., \& Kim, N. (2007). Past research in instructional technology: Results of a content analysis of empirical studies published in three prominent instructional technology journals from the year 2000 through 2004. Journal of Educational Computing Research, 36 (3), 269-300. https://doi.org/10.2190/K3P8-8164-L56J-33W4

Hranstinski, S. \& Keller, C. (2007). An examination of research approaches that underlie research on educational technology: A review from 2000 to 2004. Journal of Educational Computing Research, 36 (2), 175-190. https://doi.org/10.2190/H16L-4662-6000-0446

Hwang, G. J. \& Tsai, C. C. (2011). Research trends in mobile and ubiquitous learning: A review of publications in selected journals from 2001 to 2010. British Journal of Educational Technology, 42(4), E65-E70. https://doi.org/10.1111/j.1467-8535.2011.01183.x

Ioannidou, A., Repenning, A., \& Webb, D. C. (2009). AgentCubes: Incremental 3D end-user development. Journal of Visual Languages \& Computing, 20(4), 236-251. https://doi.org/10.1016/j.jvlc.2009.04.001

Israel, M., Pearson, J. N., Tapia, T., Wherfel, Q. M., \& Reese, G. (2015). Supporting all learners in school-wide computational thinking: A cross-case qualitative analysis. Computers \& Education, 82, 263-279. https://doi.org/10.1016/j.compedu.2014.11.022

ISTE. (2016). CT leadership toolkit. Retrived on January 21, 2016, from http://www.iste.org/ docs/ct-documents/ct-leadershipt-toolkit.pdf?sfvrsn=4

ISTE and CSTA. (2011). Operational definition of computational thinking for $K-12$ education. Retrieved on March 25, 2016, from http://www.iste.org/docs/ctdocuments/computational-thinking-operational-definition-flyer.pdf?sfvrsn=2

Jenkins, C. (2015). Poem generator: A comparative quantitative evaluation of a microworlds based learning approach for teaching English. International Journal of Education and Development using Information and Communication Technology, 11(2), 153.

Jun, S., Han, S., Kim, H., \& Lee, W. (2014). Assessing the computational literacy of elementary students on a national level in Korea. Educational Assessment, Evaluation and Accountability, 26(4), 319-332. https://doi.org/10.1007/s11092-013-9185-7

Kafai, Y. B. \& Burke, Q. (2013). Computer programming goes back to school. Phi Delta Kappan, 95(1), 61-65. https://doi.org/10.1177/003172171309500111

Kim, B., Kim, T., \& Kim, J. (2013). Paper-and-pencil programming strategy toward computational thinking for non-majors: Design your solution. Journal of Educational Computing Research, 49(4), 437-459. https://doi.org/10.2190/EC.49.4.b

Kirk, J. \& Miller, M. L. (1986). Reliability and validity in qualitative research. Sage.

Kucuk, S., Aydemir, M., Yildirim, G., Arpacik, O., \& Goktas, Y. (2013). Educational technology research trends in Turkey from 1990 to 2011. Computers \& Education, 68, 42-50. https://doi.org/10.1016/j.compedu.2013.04.016

Lim, S. (2015). Designing a literature instruction using big data. Advanced Science and Technology Letters, 97, 82-87. http://dx.doi.org/10.14257/astl.205.97.14

Lomax, R. G. \& Hahs-Vaughn, D. L. (2012). An introduction to statistical concepts (3rd ed.). New York: Taylor and Francis Group.

Lu, J. J. \& Fletcher, G. H. L. (2009). Thinking about computational thinking. ACM SIGCSE Bulletin, 41(1), 260. https://doi.org/10.1145/1539024.1508959 
Manson, J. R. \& Olsen, R. J. (2010). Diagnostics and rubrics for assessing learning across the computational science curriculum. Journal of Computational Science, 1(1), 55-61. https://doi.org/10.1016/j.jocs.2010.03.012

Marshall, C. \& Rossman, G. B. (2014). Designing qualitative research (6th ed.). New York: Sage.

Merriam, S. B. \& Tisdell, E. J. (2015). Qualitative research: A guide to design and implementation. New York: John Wiley \& Sons.

Miller, C. S., \& Settle, A. (2011). When practice doesn't make perfect: Effects of task goals on learning computing concepts. ACM Transactions on Computing Education (TOCE), 11(4), 22. https://dl.acm.org/citation.cfm?doid=2048931.2048933

Moreno-León, J., Robles, G., \& Román-González, M.(2015). Dr. Scratch: Automatic analysis of Scratch projects to assess and foster computational thinking. RED. Revista de Educación a Distancia, 15(46), 1-23.

Mohaghegh, M. \& McCauley, M. (2016). Computational thinking: The skill set of the 21st century. International Journal of Computer Science and Information Technologies (IJCSIT), 7(3), 1524-1530.

Navlakha, S. \& Bar-Joseph, Z. (2011). Algorithms in nature: The convergence of systems biology and computational thinking. Molecular systems biology, 7(1), 546. . https://doi.org/10. 1038/msb.2011.78

Olabe, X. B., Basogain, M. A. O., \& Basogain, J. C. O. (2015). Computational thinking trough programming: A learning paradigm. RED-Revista De Educacion A Distancia, 46(6), 1-33.

Papert, S. (1996). An exploration in the space of mathematics educations. International Journal of Computers for Mathematical Learning, 1(1), 95-123.

Patton, M. Q. (2014). Qualitative research \& evaluation methods: Integrating theory and practice (4th ed.). New York: Sage.

Pellas, N. \& Peroutseas, E. (2016). Gaming in Second Life via Scratch4SL: Engaging high school students in programming courses. Journal of Educational Computing Research, 54(1), 108-143. https://doi.org/10.1177/0735633115612785

Psycharis, S. (2016). Inquiry based-computational experiment, acquisition of threshold concepts and argumentation in science and mathematics education. Educational Technology \& Society, 19(3), 282-293.

Repenning, A., Webb, D. C., Brand, C., Gluck, F., Grover, R., Miller, S., ... \& Song, M. (2014). Beyond Minecraft: Facilitating computational thinking through modeling and programming in 3d. IEEE Computer Graphics and Applications, 34(3), 68-71. https://doi.org/10.1109/MCG.2014.46

Repenning, A., Webb, D. C., Koh, K. H., Nickerson, H., Miller, S. B., Brand, C., ... \& Repenning, N. (2015). Scalable game design: A strategy to bring systemic computer science education to schools through game design and simulation creation. ACM Transactions on Computing Education (TOCE), 15(2), 11. https://doi.org/10.1145/2700517

Riley, D. D. \& Hunt, K. A. (2014). Computational thinking for the modern problem solver. Florida: CRC Press.

Ross, S. M., Morrison, G. R., \& Lowther, D. L. (2010). Educational technology research past and present: Balancing rigor and relevance to impact school learning. Contemporary Educational Technology, 1(1), 17-35. 
Selby, C. C. (2014). How can the teaching of programming be used to enhance computational thinking skills? (Unpublished doctoral dissertation). University of Southampton, Southampton.

Shell, D. F. \& Soh, L. K. (2013). Profiles of motivated self-regulation in college computer science courses: Differences in major versus required non-major courses. Journal of Science Education and Technology, 22(6), 899-913. https://doi.org/10.1007/s10956-013-9437-9

Shih, M. L., Feng, J., \& Tsai, C. C. (2008). Research and trends in the field of e-learning from 2001 to 2005: A content analysis of cognitive studies in selected journals. Computers \& Education, 51(2), 955-967. https://doi.org/10.1016/j.compedu.2007.10.004

Simsek, A., Ozdamar, N., Uysal, O., Kobak, K., Berk, C., Kilıcer, T., \& Cigdem, H. (2009). Current trends in educational technology research in Turkey in the new millennium. Educational Sciences: Theory \& Practice, 9(2), 941-996.

Snodgrass, M. R., Israel, M., \& Reese, G. C. (2016). Instructional supports for students with disabilities in K-5 computing: Findings from a cross-case analysis. Computers \& Education, 100, 1-17. https://doi.org/10.1016/j.compedu.2016.04.011

Sorguc, A. G. (2013). Computational Models in Architecture: Understanding MultiDimensionality and Mapping. Nexus Network Journal, 15(2), 349-362. https://doi.org/10.1007/s00004-013-0150-z

Srihari, S. N. \& Singer, K. (2014). Role of automation in the examination of handwritten items. Pattern Recognition, 47(3), 1083-1095. https://doi.org/10.1016/j.patcog.2013.09.032

Sullivan, F. R. \& Heffernan, J. (2016). Robotic construction kits as computational manipulatives for learning in the STEM disciplines. Journal of Research on Technology in Education, 48(2), 105-128. https://doi.org/10.1080/15391523.2016.1146563

Tahy, Z. S. (2016). How to teach programming indirectly - Using spreadsheet application. Acta Didactica Napocensia, 9(1), 15-22.

Vallance, M. \& Towndrow, P. A. (2016). Pedagogic transformation, student-directed design and computational thinking. Pedagogies: An International Journal, 11(3), 218-234. https://doi.org/10.1080/1554480X.2016.1182437

Voogt, J., Fisser, P., Good, J., Mishra, P., \& Yadav, A. (2015). Computational thinking in compulsory education: Towards an agenda for research and practice. Education and Information Technologies, 20(4), 715-728. https://doi.org/10.1007/s10639-015-9412-6

Wang, D., Wang, T., \& Liu, Z. (2014). A tangible programming tool for children to cultivate computational thinking. The Scientific World Journal, 2014, 1-10. http://dx.doi.org/10.1155/2014/428080

Weber, R.P. (1988), Basic Content Analysis, Sage University Paper Series on Quantitative Applications in the Social Sciences, Series No. 07-049, Sage, Beverly Hills, CA, and London

Weintrop, D. (2016). Modality matters: Understanding the effects of programming language representation in high school computer science classrooms (Unpublished Doctoral Dissertation), Northwestern University.

Weintrop, D., Holbert, N., Horn, M. S., \& Wilensky, U. (2016). Computational thinking in constructionist video games. International Journal of Game-Based Learning (IJGBL), 6(1), 1-17. 
Werner, L., Denner, J., \& Campe, S. (2015). Children programming games: A strategy for measuring computational learning. ACM Transactions on Computing Education (TOCE), 14(4), 24. https://doi.org/10.1145/2677091

Willis, J. W. (2008). Qualitative research methods in education and educational technology. USA: Age Publishing.

Wilkerson-Jerde, M. H. (2014). Construction, categorization, and consensus: Student generated computational artifacts as a context for disciplinary reflection. Educational Technology Research and Development, 62(1), 99-121. https://doi.org/10.1007/s11423-013-9327-0

Wing, J. M. (2006). Computational thinking. Communications of The ACM, 49(3), 33-35.

Wing, J. M. (2008). Computational thinking and thinking about computing. Philosophical Transactions of The Royal Society A: Mathematical, Physical And Engineering Sciences, 366(1881), 3717-3725. https://doi.org /10.1098/rsta.2008.0118

Wing, J., Henderson, P., Hazzan, O., \& Cortina, T. (2005). Computational thinking. Retrieved on April 21, 2016, from http://www.cs.cmu.edu/afs/cs/usr/wing/www/ct-paper.pdf.

Xu, Z. W. \& Tu, D. D. (2011). Three new concepts of future computer science. Journal of Computer Science and Technology, 26(4), 616-624. https://doi.org/10.1007/s11390-0111161-4

Yadav, A., Hong, H., \& Stephenson, C. (2016). Computational thinking for all: Pedagogical approaches to embedding 21st century problem solving in $\mathrm{k}-12$ classrooms. TechTrends, 60(6), 565-568. https://doi.org/10.1007/s11528-016-0087-7

Yadav, A., Mayfield, C., Zhou, N., Hambrusch, S., \& Korb, J. T. (2014). Computational thinking in elementary and secondary teacher education. ACM Transactions on Computing Education (TOCE), 14(1), 5. https://doi.org/10.1145/2576872

Zapata-Ros, M. (2015). Pensamientocomputacional: Unanuevaalfabetización digital. Revista de Educación a Distancia, (46).

Correspondence: Ulas Ilic, Research Assistant, Department of Computer Education and Instructional Technology, Faculty of Education, Pamukkale University, Denizli, Turkey 